\title{
Ovarian function and reproductive outcome (4) after ovarian tissue transplantation: a systematic review
}

\author{
Sepideh Sheshpari ${ }^{1 \dagger}$, Mahnaz Shahnazi ${ }^{1}$, Halimeh Mobarak² Shahin Ahmadian ${ }^{3 \dagger}$, Alberto Miranda Bedate ${ }^{4}$, \\ Ziba Nariman-Saleh-Fam ${ }^{5}$, Mohammad Nouri ${ }^{7,8}$, Reza Rahbarghazi ${ }^{6,7}$ and Mahdi Mahdipour ${ }^{7,8^{*}}$ (D)
}

\begin{abstract}
The aim of this systematic review study is to summarize the current knowledge of ovarian tissue transplantation and provide insight on ovarian function, fertility and reproductive outcome following ovarian tissue transplantation. Relevant studies were identified by searching through PubMed, Cochrane Library, Embase, ProQuest, and Scopus databases until August 2018. Ovarian function by examination of the hormonal level was evaluated, together with follicular growth, the return of menstrual cycle and assessment of reproductive consequences: pregnancy, miscarriage rates and live birth after transplantation. Studies including female patients aged between 22 and 49 years that were subjected to ovarian tissue transplantation were considered. A total of 1185 studies were identified in the primary search. Titles and abstracts were screened for assessment of the inclusion criteria. Finally, twenty-five articles met the criteria and were included in this study. In general, $70 \%$ of patients that underwent ovarian tissue transplantation had ovarian and endocrine function restoration as well as follicular growth. Pregnancy was reported with $52 \%$ of the patients. The available evidence suggests that ovarian tissue transplantation is a useful and an applied approach to restore hormonal function, endocrine balance and eventually fertility outcomes in patients that are predisposed to lose their fertility, diagnosed with premature ovarian failure (POF), as well as women undergoing cancer treatments. Identification of the techniques with the lowest invasions for follicular and oocyte development after ovarian tissue transplantation aiming to reduce probable adverse effects after treatment is indispensable.
\end{abstract}

Keywords: Ovarian tissue, Transplantation, Cryopreservation, Fertility, Pregnancy

\section{Introduction}

In the past decades, the life expectancy of patients diagnosed with most forms of cancers has increased due to improved and novel therapeutics [1], highlighting the importance of quality of life after treatment. Besides the increased efficiency of anti-cancer treatments such as chemotherapy and radiotherapy, there are also negative side effects, especially on the reproductive system that affect fertility [2,3]. Following the use of alkylating agents

\footnotetext{
*Correspondence: mahdipourm@tbzmed.ac.ir

†Sepideh Sheshpari and Shahin Ahmadian are considered as co-first authors

${ }^{7}$ Stem Cell Research Center, Tabriz University of Medical Sciences,

Tabriz 5166615739, Iran

Full list of author information is available at the end of the article
}

and ionizing radiation in cancer treatment, endocrine activity and ovarian function can be severely compromised. A profound reduction in ovarian follicle numbers coincides with ovarian damage following chemotherapy, and close relationships exist between patient's age, drug dosage and risk of losing ovarian function [2]. Chemotherapy, particularly when alkylating agents are used, can lead to premature ovarian failure (POF) as one of the complications [3]. POF is known as an ovarian function insufficiency affecting about $1 \%$ of women before the age of 40 [4], whereas over one-third of women undergoing chemotherapy procedures suffer from POF [5]. Male cancer patients are not exempt from post-treatment complications and also require attention to assist the return of their reproductive function [2]. 
Various assisted reproductive techniques are being offered for female patients before and after therapy such as oophoropexy for radiation shielding, fertility-sparing surgery, egg and embryo freezing, ovarian tissue cryopreservation and transplantation [6]. Despite the fertility preservation options present today, in some cases it is important to begin treatment without any delay. In addition, in prepubertal patients, ovarian stimulation to obtain oocytes is not considered. For those patients it can be beneficial to remove the ovarian tissue via laparoscopy followed by tissue cryopreservation. When the patients are recovered the preserved tissue could be transplanted to its original or heterotopic site [7]. Ovarian tissue transplantation can restore endocrine function and fertility in women with premature ovarian insufficiency [8]. The first successful fresh ovarian tissue transplantation leading to living birth in primates was reported in 2004 [9]. In another study, Donnez et al. transplanted ovarian tissue 6 years after the diagnosis of Hodgkin's lymphoma. An improved ovarian function was observed 5 months after transplantation and was followed by a live birth [7]. About type of transplant, in auto-transplantation, fresh or cryopreserved ovarian tissue is transplanted to the same person, or to identical twin sister, [10] whereas in allotransplantation the patient receives tissue from a genetically different HLA matched-donor. Both fresh and frozen ovarian tissue transplantations have been reported to yield similar outcomes considering menstrual cycle return and ovarian function restoration [11]. In Fig. 1, the processes of cryopreservation and transplantation are summarized. Vitrification and slow freezing are two common techniques applied for ovarian tissue cryopreservation. In slow freezing technique, low level of follicular degradation and higher degree of tissue survival and follicular counts were notified, however, no significant differences were reported between these techniques [12, 13]. This study makes an inventory and summarizes the current knowledge of ovarian tissue transplantation and its success or failure to maintain fertility, restore reproductive capacity and preserve ovarian function. The current systematic review evaluates the success rate of ovarian transplantation and proposes a guideline for fertility preservation in the future.

\section{Methods}

The paper was prepared based on the standards and guidelines of the Preferred Reporting Items for Systematic Reviews (PRISMA) [14]. All data originate from previously published experiments in international peerreviewed journals.

\section{Search strategy, data extraction, and eligibility criteria}

Relevant studies were identified by searching through PubMed, Cochrane Library, Embase, ProQuest, and Scopus databases until August 2018 with the following keywords: "ovarian tissue transplantation", "ovary transplantation", "ovarian implantation", "ovary implantation", "ovarian tissue allografting", "ovarian

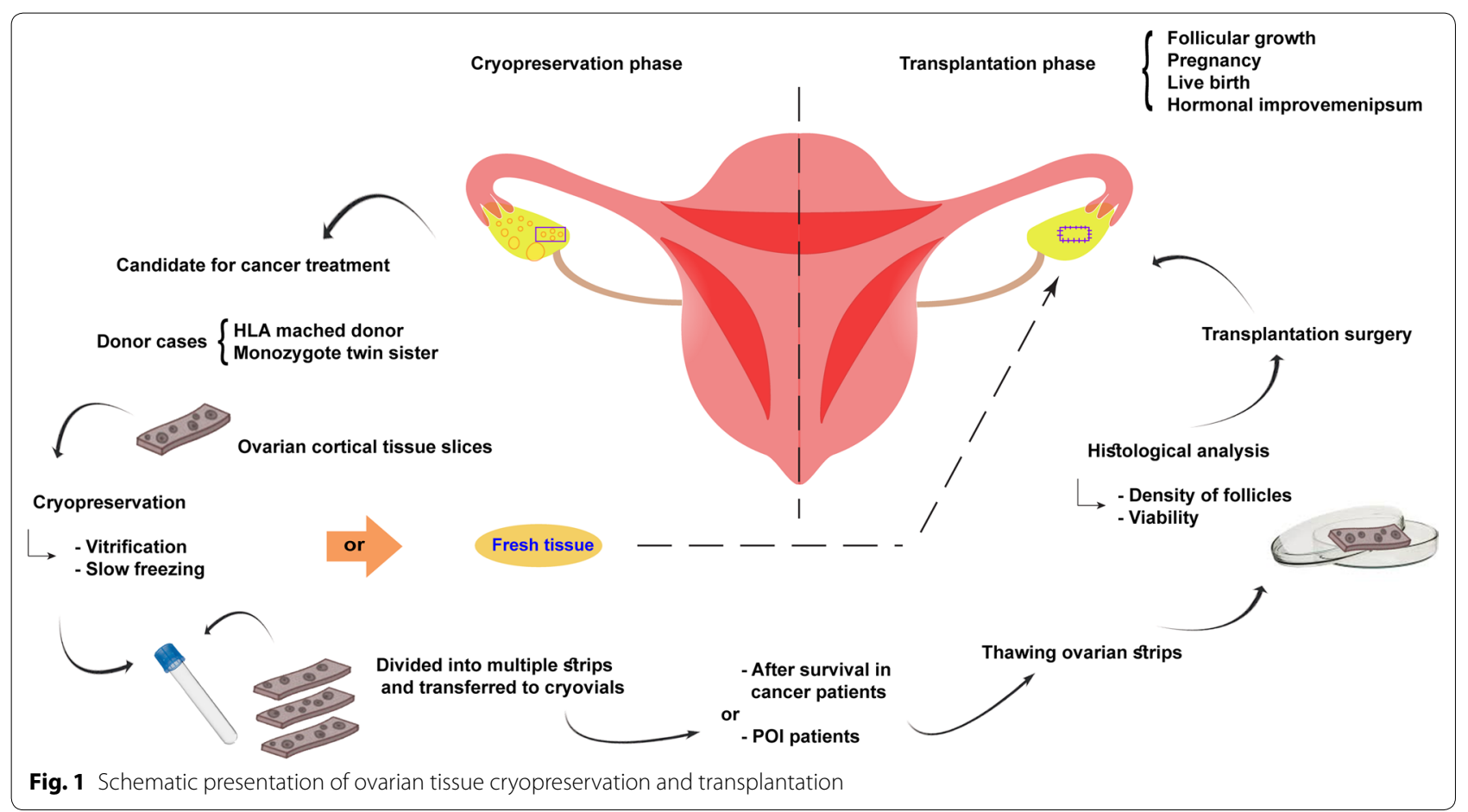


auto-transplantation", "ovary allografting", "birth rate", "live birth", "pregnancy", "pregnancy rate", "chemical pregnancy", "clinical pregnancy", "AMH", "anti Mullerian hormone", "follicular stimulating hormone", "FSH", "atrial follicle count", "fertilization", "fertility rate", "reproductive capacity", and "treatment of infertility" in human studies. References were collected in EndNote X7.1 (Thomson Reuters, USA).

\section{Study selection}

After the primary search, title and abstract of studies were first evaluated by three authors of this paper (H.M, $\mathrm{S} . \mathrm{SH}$, and SH.A). If the abstracts fulfilled the general aspect of the review, the full text was considered. Inclusion criteria such as written language (English), article type (original article), intervention (ovarian tissue transplant) and outcome (hormone and ovarian tissue function and fertility) were regarded to select the full text of the remaining articles in the study. The term transposition instead of transplantation, non-English language and cryopreservation of ovarian tissue without transplantation were used as the exclusion criteria. Authors independently reviewed the selected published articles. The eligible studies had the methodological characteristics such as type of the study, number of participants and their disease condition, type of interventions, number of patients that underwent ovarian tissue transplantation, age at the time of intervention, outcomes and an approximate follow-up duration in the post-intervention period. Any disagreements that arose between the reviewers were resolved through discussion, or with a fourth reviewer (M. M). Relevant data were summarized in a tabular format in a systematic manner (Table 1).

\section{Outcomes measures}

The primary outcome of this systematic review was to assess systemic levels of follicle stimulating hormone (FSH), Luteinizing hormone (LH), anti Mullerian hormone (AMH), and inhibin as well as follicular growth, and the return of a menstrual cycle after ovarian tissue transplantation. Pregnancy rates, live births, and in vitro fertilization (IVF) consequences were considered as secondary outcomes.

\section{Results}

A total of 1192 studies were identified in the primary search (Fig. 2). Among these studies, titles and abstracts were carefully reviewed by independent reviewers assessing whether they could meet the Eligibility Criteria. At this stage, 612 studies were excluded since they did not match the inclusion criteria of the study. Finally, 29 unique reports, including cohort articles and case reports, were enrolled in this study. The selected articles were critically appraised by reviewers for methodological quality.

\section{Clinical characteristics of the selected studies}

In the included studies, a total of 693 patients underwent ovarian cryopreservation whereas only 210 patients were subjected to ovarian tissue transplantation. Among transplant recipients, 29 patients received fresh ovarian tissue, out of which 26 received transplants from their twin sisters or HLA-matched donors and 3 cases received their own ovaries; 11 patients received allogenic frozen tissue, and 170 received their own frozen ovarian tissue. The mean age for transplantation was 31 years; with the youngest patient being a 22 years old women cured from Hodgkin lymphoma, without children. The oldest patient in the included manuscripts was 49 years old and ovarian tissue was grafted ectopically in her arm to prevent the occurrence of menopause [26].

The most common reason for ovarian tissue transplantation was fertility preservation cancer treatment (165 cases), followed by women suffering from POF (40 cases). One patient diagnosed with a hemi-uterus had her fallopian tubes removed by laparotomy [41]. In 4 patients diagnosed with uterine leiomyoma and candidate for ovarian cancer, abdominal hysterectomy was performed with bilateral salpingo-oophorectomy and subsequently, the ovarian tissues were cryopreserved [26].

Various sites have been used for ovarian transplantation such as the abdominal rectus muscle, peritoneum, abdominal wall, adjacent ligament of the ovary, ovarian cavity and fallopian tube (Table 2). Only in one study, the transplant group was compared with ten peri-menopausal patients as a control group for hormonal evaluation [26]. Some subjects were excluded from the studies since they either had less follow-up duration or were lost to follow-up [30, 34, 37, 40].

In total, 210 patients underwent a single transplantation procedure whereas 27 patients received second transplantation as well. A second transplantation procedure was performed either because of recurrence of the disease or because of short-term function of the transplanted tissue.

\section{Primary outcomes}

A summary of the initial data is presented in Table 2 . Return to menstruation as one of the primary outcomes was reported to take place between 2 months [26, 28, $31,35,40]$ to 1 year after transplantation [38]. The onset of ovarian activity and hormonal function at the closest time after transplantation was 1 week; estradiol and FSH levels showed an increase and decrease patterns, respectively [41]. Some of the recipients, however, did not respond to transplantation [26, 28, 34, 36, 40]. For 


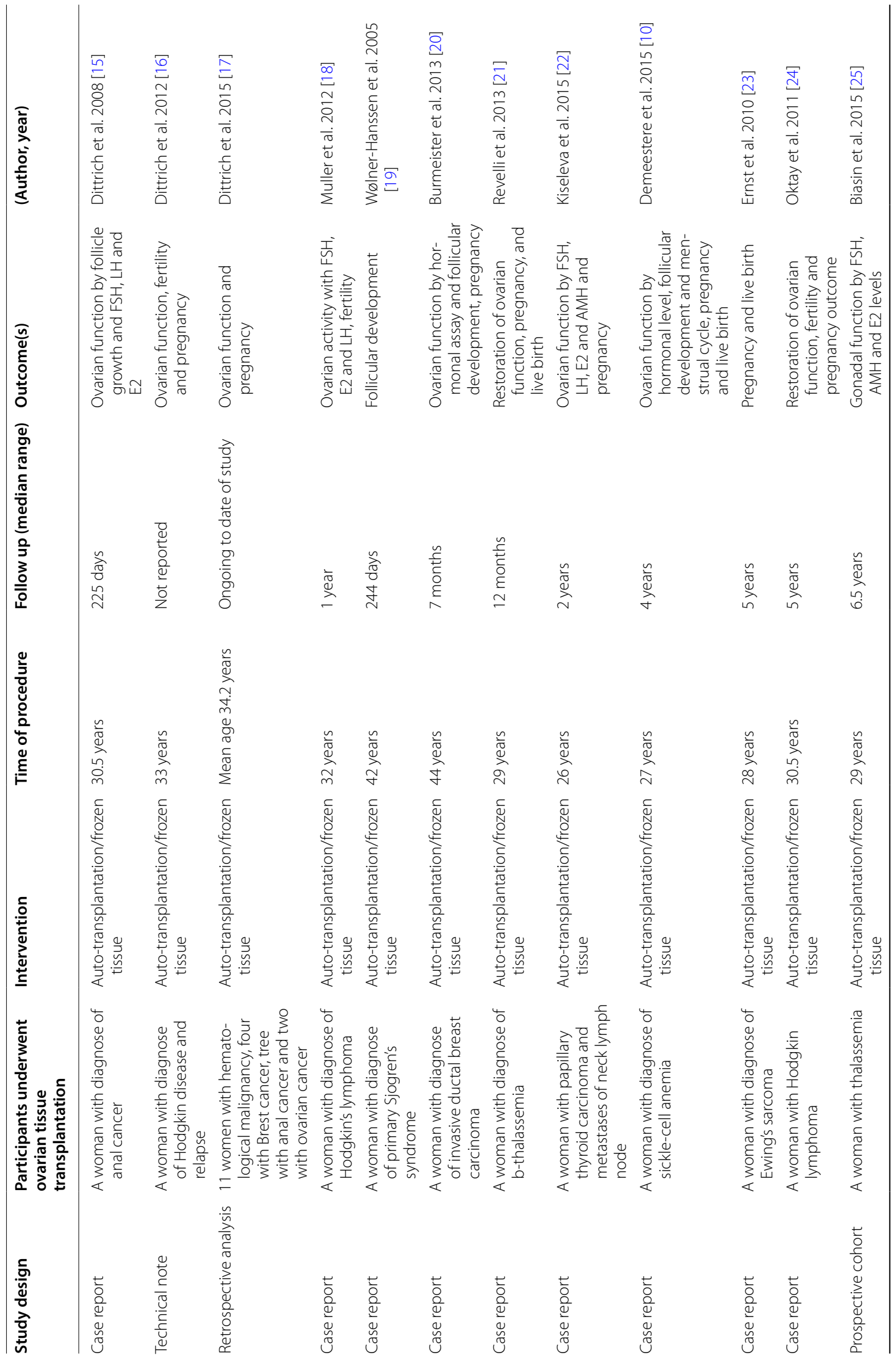


Sheshpari et al. J Transl Med ～(2019) 17:396

Page 5 of 15

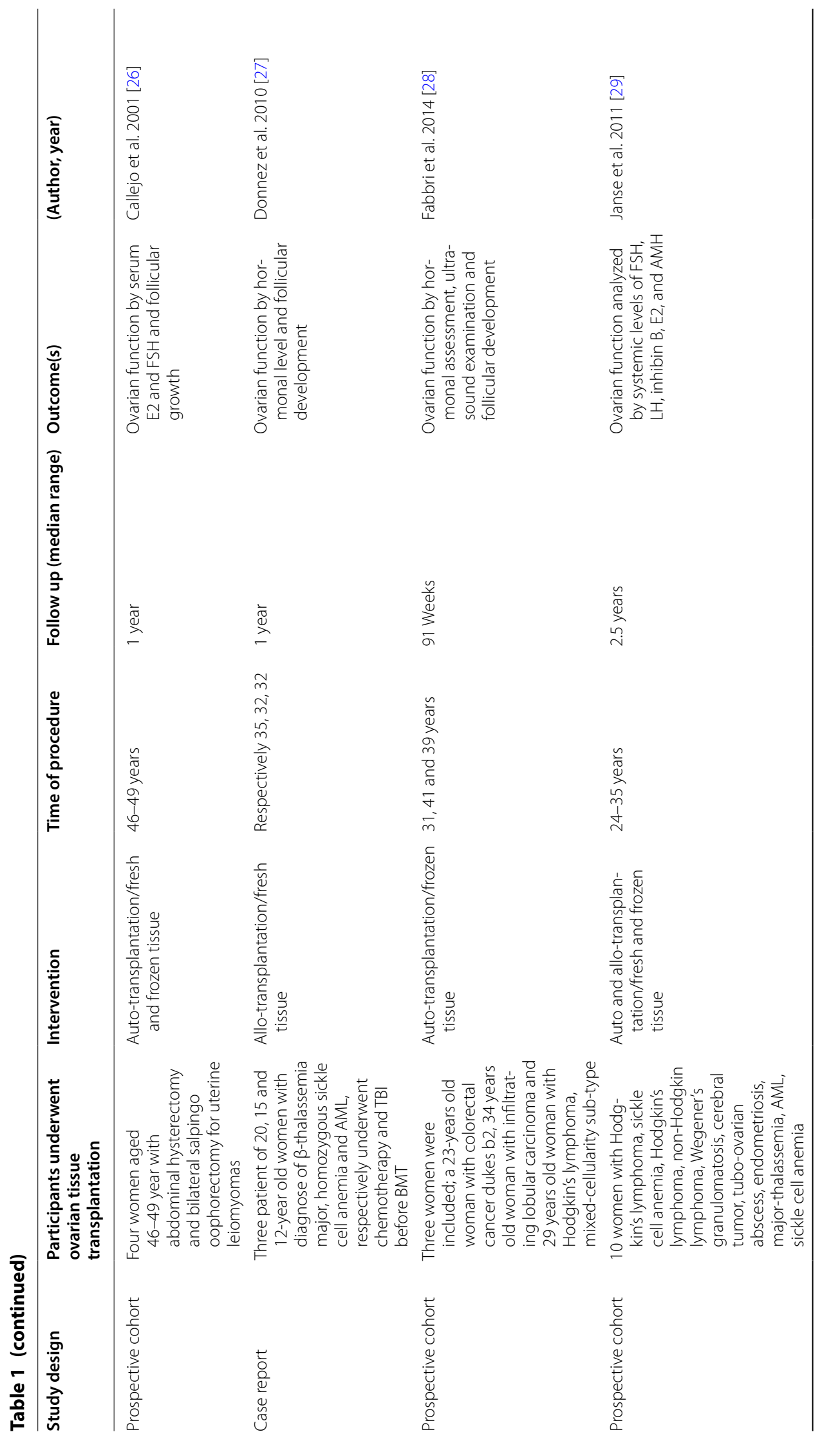




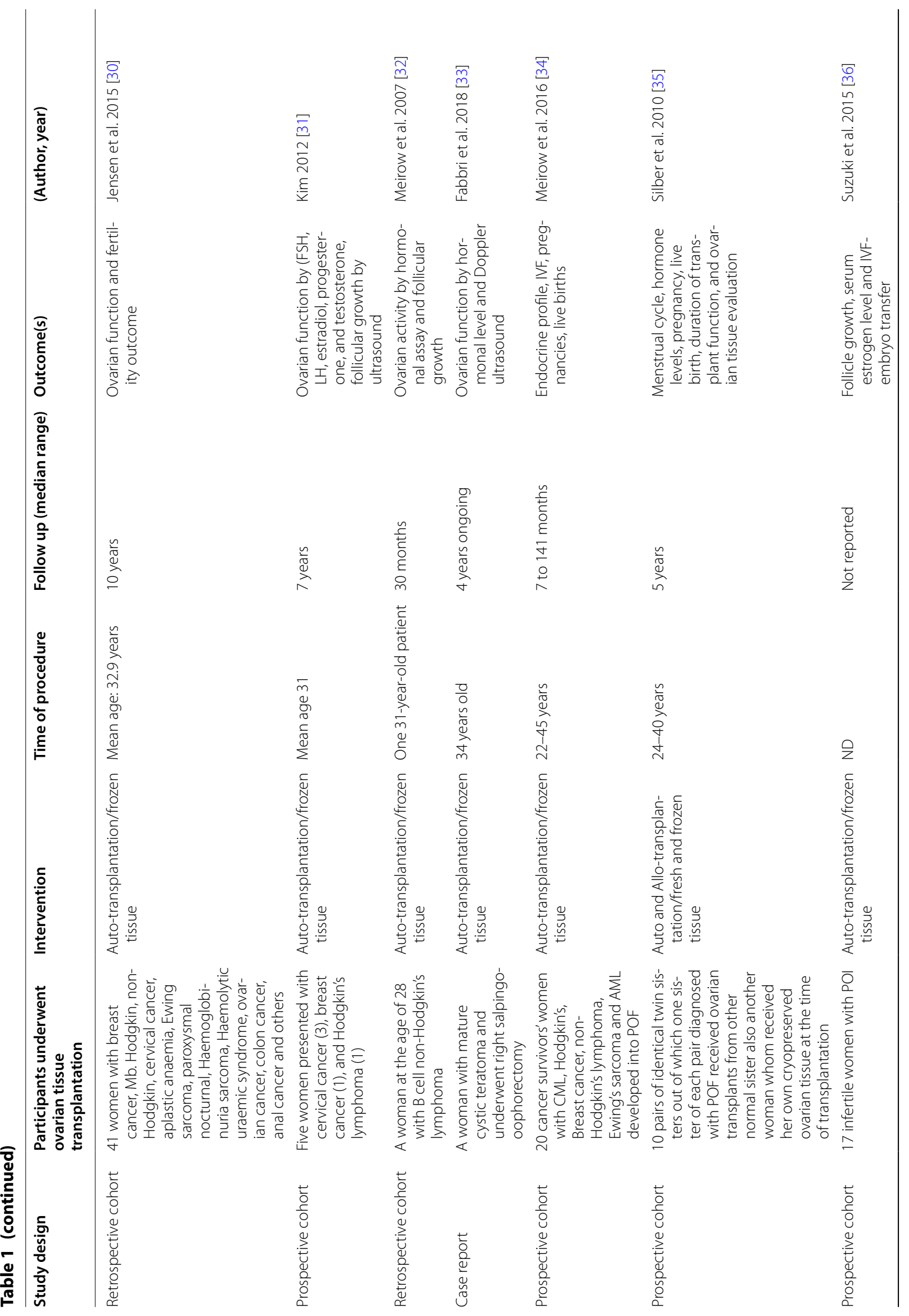




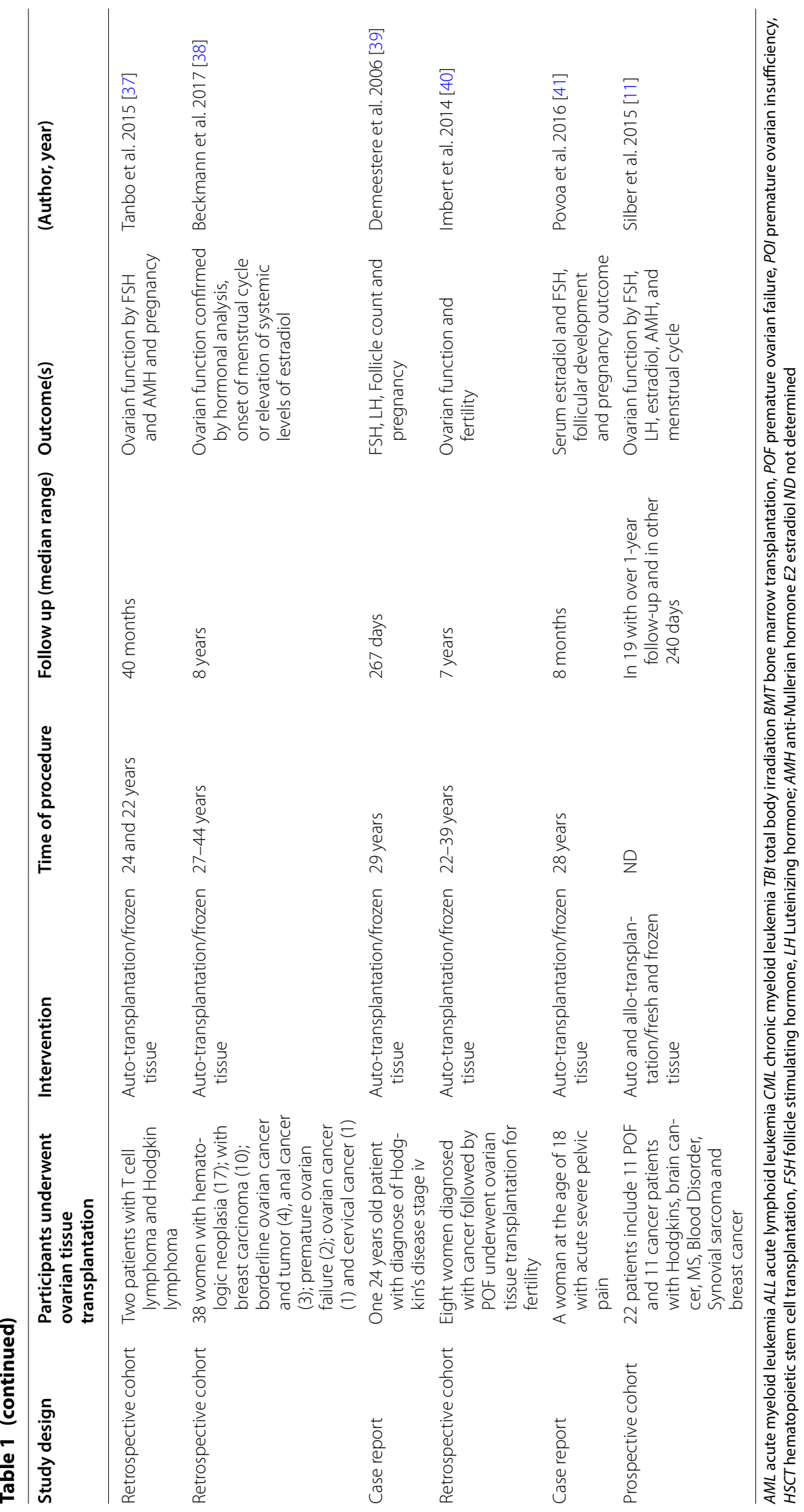




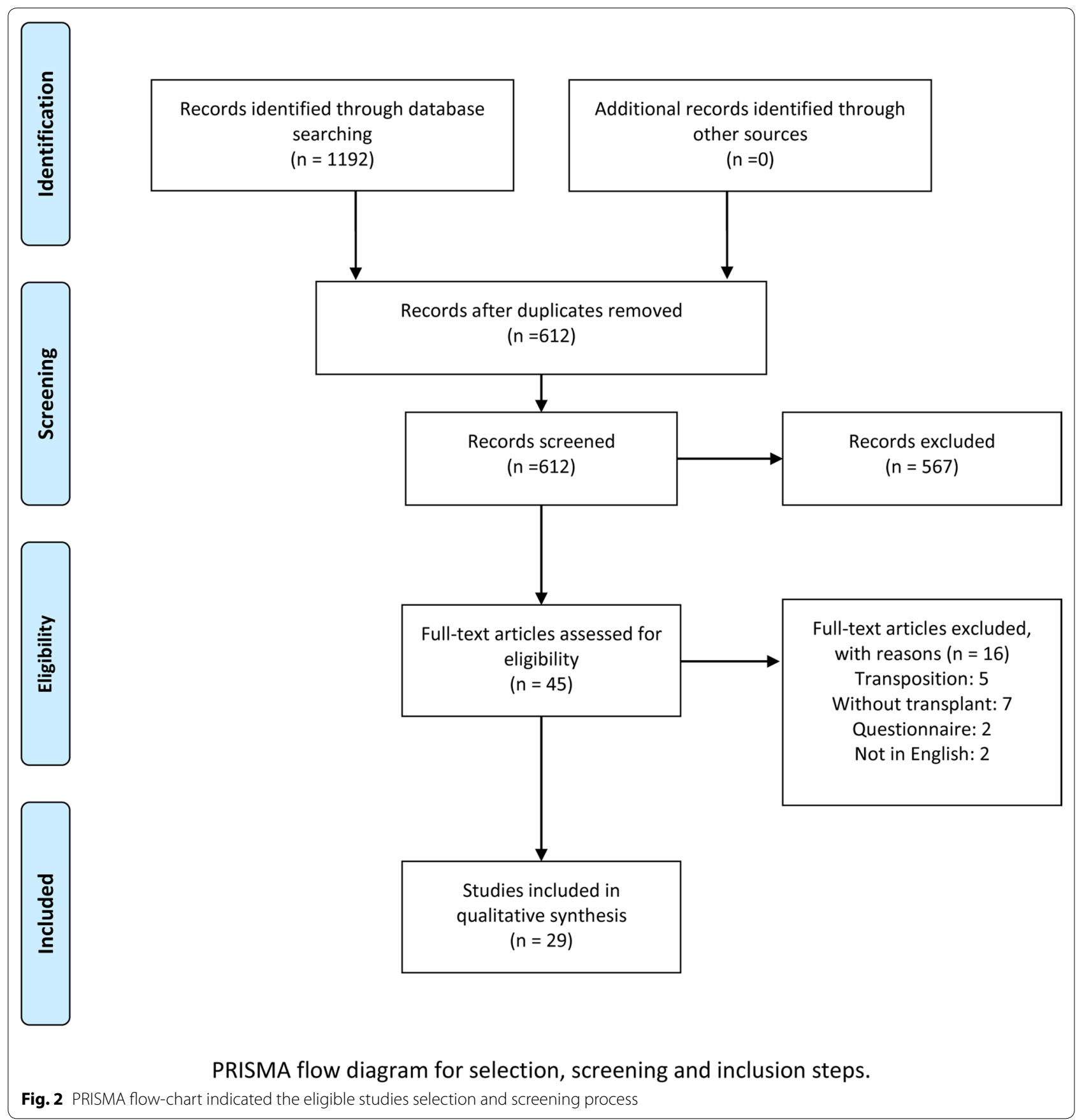

example, in Dittrich et al. study, from 20 transplant recipients just one patient showed no activity after transplantation [17], whereas in one study about 50 percent of the patients exhibited ovarian function restoration after 12 months [28]. After second transplantation, ovarian function improved at 2-4 months post-transplantation and sustained for 9-84 months [42]. The ovarian function return varied in different studies between 3 and 6 months in the single frozen transplants [31]. In a
28 years old woman diagnosed with cervical cancer, however, ovarian function retrieval was observed 84 months after the second transplant. In this patient endocrine activity was observed even 7 years after transplantation [31]. Similarly, Silber et al. reported functional ovaries even after 8 years in two women who underwent fresh ovarian transplantation after the diagnosis of POF [11].

The evaluation of hormonal function after transplantation indicated that the level of FSH declined to less than 


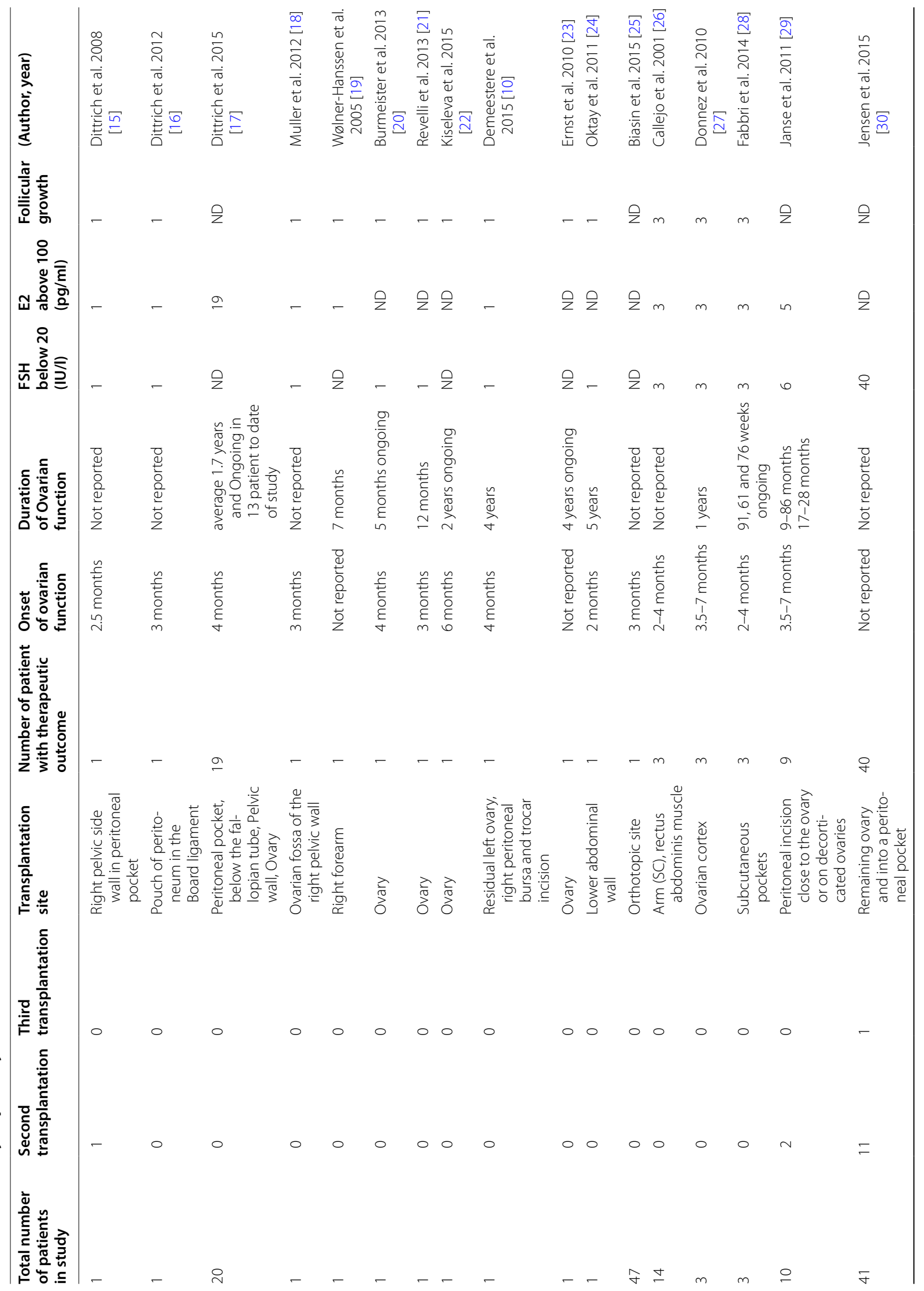




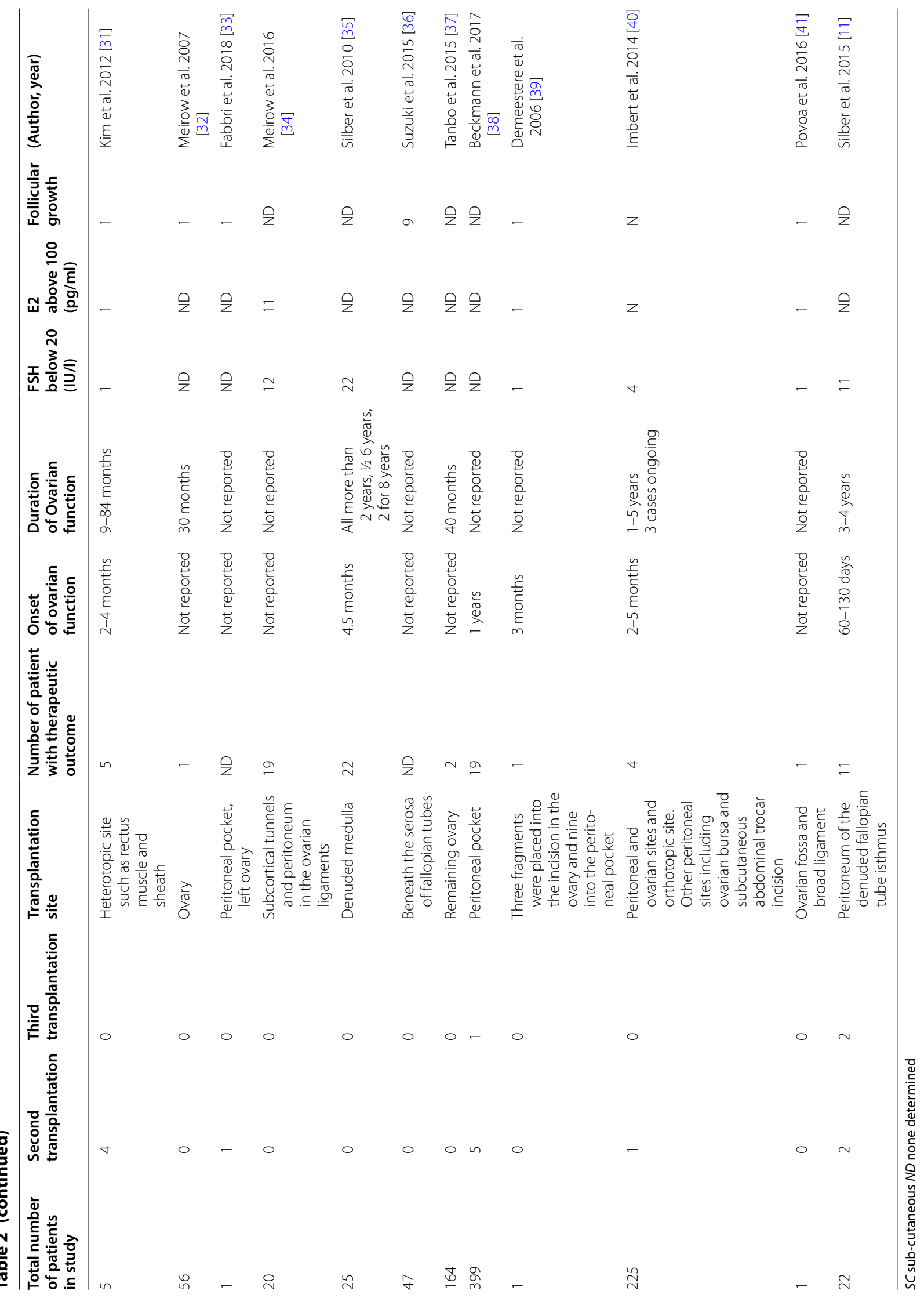


$20 \mathrm{IU} / \mathrm{l}$ in 115 subjects while E2 levels had increased to above $100 \mathrm{pg} / \mathrm{ml}$ in 41 patients. These findings illustrate the success of transplantation. AMH levels, however, did not change in these cases, except for one study [11] in which the levels of AMH had increased after transplantation while the levels of FSH initially decreased, and then returned back to the normal levels [11]. In another study, a gradual elevation of AMH levels was observed during follow-up examination [37]. The inhibin level was assessed in various patients where it showed an increasing pattern $[29,39]$.

Dietrich et al. reported that the development of transplanted ovarian tissue in the pelvic wall led to the typical neo-ovarian regeneration [17]. The results from ovarian transplantation at different sites illustrated that the peritoneal cavity with a decent blood supply is a putative location for transplantation purposes in which a higher ratio of follicular development as well as higher number of antral follicles was observed [43].

Evaluation of follicular growth post-transplantation has been performed in some of the studies using ultrasonography, abdominal doppler, or vaginal echography, either for one or both ovaries [41]. Callejo et al. using ultrasonography and doppler identified the successful growth of follicles (one follicle with a $16 \mathrm{~mm}$ diameter) with surrounding blood flow in ovarian tissue transplanted to the abdominal rectus muscle [26]. In this line, Muller et al. confirmed the follicular growth (17 to $18 \mathrm{~mm}$ in diameter) using sonography, and subsequently ovulation induction was performed. Following a natural conception and a successful pregnancy, a healthy baby was born [18]. In another trial, dominant follicles were detected in ovaries transplanted to the peritoneum [39].

\section{Secondary outcomes}

From the total number of 210 subjects who received the transplants, some failed to exhibit the desired secondary outcomes, out of which, several patients (age range 49-46 years) underwent bilateral hysterectomy and adnexectomy in order to prevent the symptoms of menopause [26]. Some patients did not attempt to maintain fertility $[27,31]$ as well as a single case of bilateral agenesis of fallopian tubes [35]. Out of remaining cases, 84 spontaneous and 36 IVF pregnancies, 80 live births, 22 abortions and 1 ectopic pregnancy were obtained (Table 3).

Of 29 recipients of fresh ovarian tissue transplantation, 26 subjects confirmed to be pregnant out of which 19 live births were reported with one confirmed pregnancy ongoing (20th week) at the end of the study. Of 181 frozen tissue recipients, 96 pregnancies and 86 live births were reported, with 8 continuing pregnancies at the end of the study.
The youngest worldwide reported case of ovarian tissue preservation and transplantation before puberty was a 9-year-old girl diagnosed with beta-thalassemia. In this specific patient, ovarian tissue was transplanted 14 years after cryopreservation and the normal ovarian function and pregnancy was confirmed following IVF [44]. In a similar case, a successful spontaneous pregnancy followed by live birth was reported for a patient who received ovarian tissue 10 years after removal at the age of 13 [10].

Considering other secondary outcomes, 11 embryos were obtained as a result of IVF cycles $[23,31,40]$. The summarized illustration of cryopreservation, transplantation, and IVF is shown in Fig. 3.

Regarding post-transplantation complications, among the reported abortions, one case has been diagnosed with chromosome 10 tetrasomy resulting in abortion at week 7 of pregnancy [39]. Seventeen cases of spontaneous abortion were described [11, 17, 33-35], and abortion was induced in 5 cases due to medical or personal issues (Table 3).

\section{Discussion \\ The difference between fresh and frozen tissue transplantation}

The selected papers described 181 patients that received frozen and 29 patients received fresh tissues; in 4 studies, patients received both fresh and frozen ovarian tissue $[11,26,29,35]$. According to most studies, there was no significant difference regarding the function of the grafted ovaries whether fresh or frozen. In both fresh and frozen tissue recipients, ovarian activity was rejuvenated after 3-4 months [26]. In Janse et al. study, first menstruation in both fresh and frozen tissue recipients occurred after an average of 4.7 months [29]. In another study, no statistically significant differences were achieved related to FSH levels of the fresh and frozen tissue groups [35]. In a study by Silber et al. 4.5 months after the transplant, all recipients, both fresh and frozen, reached normal hormonal levels, exhibited ovulation and returned to a menstrual cycle within 130 days post-transplantation and the performance of fresh and frozen tissues was similar in both groups at least until 2 years after transplantation [11].

Our investigations illustrate the restoration of reproductive and endocrine function in most of the patients following ovarian tissue transplantation. In general, over $78 \%$ of the patients who received fresh or frozen ovarian tissue showed ovarian function restoration and in over $58 \%$ of patients, pregnancies occurred. Overall, $65 \%$ of live births were achieved in fresh tissue and $45 \%$ in frozen tissue recipients. 
Table 3 Summary of secondary outcomes from selected studies

\begin{tabular}{|c|c|c|c|c|c|c|c|}
\hline $\begin{array}{l}\text { Total } \\
\text { number } \\
\text { patients }\end{array}$ & $\begin{array}{l}\text { Type of tissue } \\
\text { (cryopreservation/ } \\
\text { fresh) }\end{array}$ & Pregnancy & $\begin{array}{l}\text { Spontaneous } \\
\text { pregnancy }\end{array}$ & IVF pregnancy & Live birth & Abortion & (Author, year) \\
\hline 1 & Cryo & - & - & - & - & - & Dittrich et al. 2008 [15] \\
\hline 1 & Cryo & 1 & 1 & - & 1 & - & Dittrich et al. 2012 [16] \\
\hline 20 & Cryo & 7 & 6 & 1 & 4 & 1 & Dittrich et al. 2015 [17] \\
\hline 1 & Cryo & 1 & 1 & - & 1 & - & Müller et al. 2012 [18] \\
\hline 1 & Cryo & - & - & - & - & - & Wølner-Hanssen et al. 2005 [19] \\
\hline 1 & Cryo & 1 & 1 & 1 & - & - & Burmeister et al. 2013 [20] \\
\hline 1 & Cryo & 1 & 1 & - & 1 & - & Revelli et al. 2013 [21] \\
\hline 1 & Cryo & 1 & - & 1 & - & - & Kiseleva et al. 2015 [22] \\
\hline 1 & Cryo & 1 & 1 & - & 1 & - & Demeestere et al. 2015 [10] \\
\hline 1 & Cryo & 2 & 1 & 1 & 2 & - & Ernst et al. 2010 [23] \\
\hline 1 & Cryo & 4 & 1 & - & 3 & 1 & Oktay et al. 2011 [24] \\
\hline 47 & Cryo & 1 & 1 & - & 1 & - & Biasin et al. 2015 [25] \\
\hline 14 & 1 cryo, 3 fresh & - & - & - & - & - & Callejo et al. 2001 [26] \\
\hline 3 & Fresh & - & - & - & - & - & Donnez et al. 2010 [27] \\
\hline 3 & Cryo & - & - & - & - & - & Fabbri et al. 2014 [28] \\
\hline 10 & 7 cryo, 3 fresh & 2 & 2 & - & - & - & Janse et al. 2011 [29] \\
\hline 41 & Cryo & 28 & 13 & 15 & 13 & 3 & Jensen et al. 2015 [30] \\
\hline 5 & Cryo & - & - & - & - & - & Kim et al. 2012 [31] \\
\hline 56 & Cryo & 1 & - & 1 & 1 & - & Meirow et al. 2007 [32] \\
\hline 1 & Cryo & - & - & - & - & - & Fabbri et al. 2018 [33] \\
\hline 20 & Cryo & 16 & 7 & 9 & 10 & 3 & Meirow et al. 2016 [34] \\
\hline 25 & 11 cryo, 11 fresh & 21 & 19 & 2 & 17 & 7 & Silber et al. 2010 [35] \\
\hline 47 & Cryo & 3 & - & 3 & 2 & 1 & Suzuki et al. 2015 [36] \\
\hline 164 & Cryo & 2 & 1 & 1 & 2 & - & Tanbo et al. 2015 [37] \\
\hline 399 & Cryo & 10 & 10 & - & 9 & - & Beckmann et al. 2017 [38] \\
\hline 1 & Cryo & 1 & 1 & - & - & 1 & Demeestere et al. 2006 [39] \\
\hline 225 & Cryo & 5 & 5 & - & 2 & 1 & Imbert et al. 2014 [40] \\
\hline 1 & Cryo & - & - & - & - & - & Povoa et al. 2016 [41] \\
\hline 22 & 11 cryo, 11 fresh & 13 & 13 & - & 9 & 4 & Silber et al. 2015 [11] \\
\hline
\end{tabular}

Cryo cryopreserved sample, - null

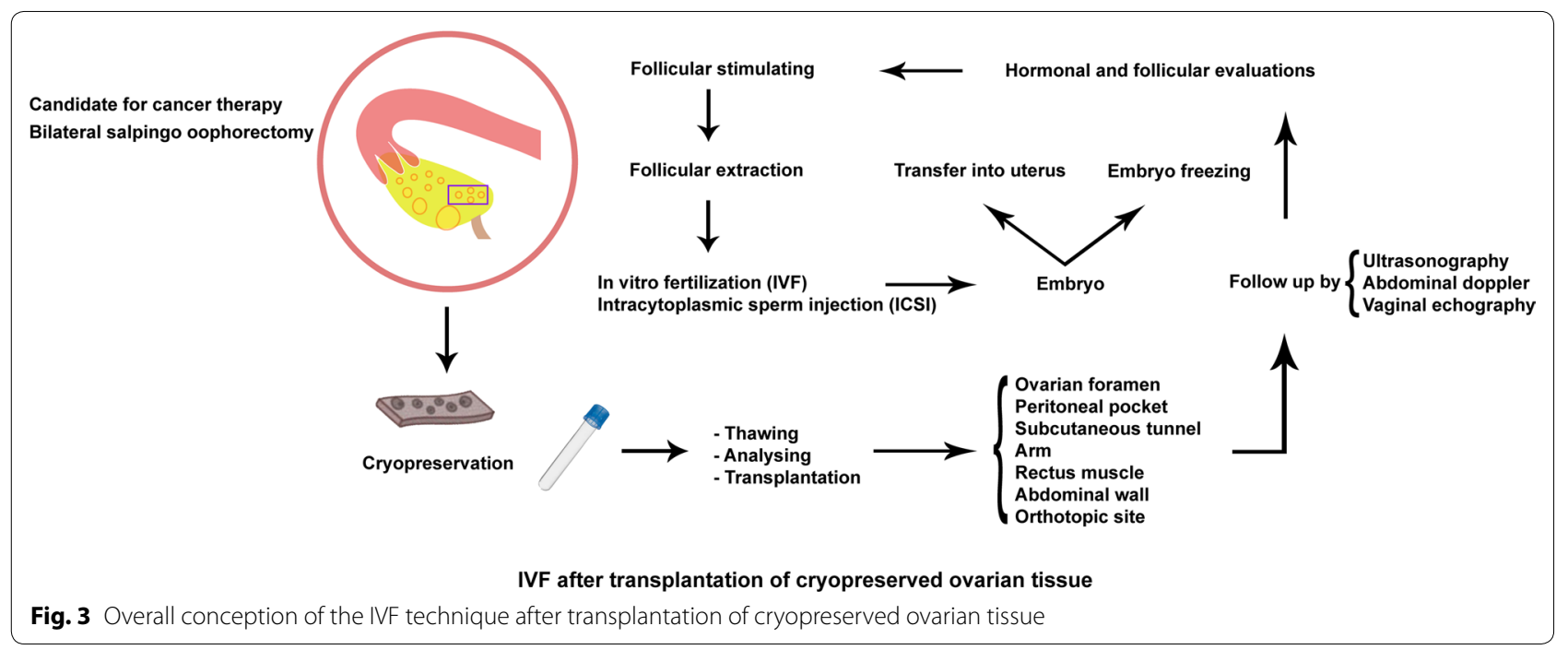


The efficacy of fresh and frozen transplanted tissues from identical twin sisters or HLA-matched sisters was reported for more than 2 years, and normal hormone levels and successful ovulation was observed 4-5 months after transplantation in all subjects. Serum levels of FSH in the patients showed a decline 3 days after transplantation and reached normal levels within 150 days after transplantation [11]. These observations clearly indicate the success of ovarian tissue transplantation.

In a study to examine the longevity of the cryopreserved tissues, ovarian pieces obtained from a 27 -yearold woman were transplanted into Severe Combined Immune Deficiency (SCID) mice and monitored for 22 weeks. The results confirmed by morphology and proliferating cell nuclear antigen (PCNA) staining, indicated that cryopreservation of ovarian tissue maintains enough functionality and development of follicles, especially primordial ones post-freezing and even following transplantation of ovarian tissue [45].

Follicular count at the time of preservation is another important factor influencing ovarian tissue transplantation outcome. Biasin et al. confirmed that the functionality of ovarian tissue transplants with enough follicle counts was continued for almost 7 years with an average of 4-5 years [25]. In line with these findings, Silber reported that the duration of the ovarian function is directly linked to the ovarian reserve (primordial and antral follicle count) at the time of preservation [11]. These findings clearly illustrate that ovarian preservation at early ages with a high follicular reserve will increase the probability of success after transplantation. Indeed ovarian tissue preservation is believed to be the foremost clinical procedure for saving fertility in patients with prepubertal cancer, in which egg or embryo freezing is not possible [25].

Various anatomical sites have been practiced for ovarian tissue transplantation, and so far no significant differences in the outcomes such as follicular growth or restoration of ovarian function, were reported [39]. This is particularly important for patients who have lost their uterus and/or ovaries and were assisted to restore their endocrine functions [26]. In combination with IVF, fertility of the patient can be restored even if the ovarian tissue is not close to the oviduct [41]. On the other hand, Demeestere et al. described that orthotopic transplantation of ovarian tissue could provide a better environment, improved angiogenesis and blood supply required for the restoration of ovarian function [39]. The ovarian medulla has also been proposed as a good site for transplantation with high potential of angiogenesis [46].

Evaluation of the ovaries for possible malignancies before transplantation is a matter of utmost concern. A study done by Shaw et al. showed that transplantation of ovarian tissues from mice diagnosed with lymphoma into healthy ones caused over $90 \%$ of contamination in the recipients. Analyzing the absence or presence of malignant cells in the tissues considered in this study before tissue transplantation revealed no complications in the ovarian tissue preservation and transplantation safety [47].

\section{Cryopreservation procedure: slow freezing or vitrification?}

Ovarian tissue cryopreservation is offered to preserve fertility and reproductive performance in women who are at high risk of POF and women who are subjected to cancer therapy in which oocyte or embryo preservation is not considered [8]. Vitrification and slow freezing are the general approaches proposed for cryopreservation of the ovary [13].

Silber et al. demonstrated no significant differences between fresh and frozen tissue transplantation (slow freezing method) groups in reduction of FSH to the basal levels and return of menstruation [11]. Similarly, in the study conducted by Klocke et al. comparing the quality of follicles immediately after freezing-thawing/vitrification-warming ovarian tissue, no significant differences between the two techniques were noticed [12]. In another study, comparison between transplantation of fresh tissue, vitrification, and slow-freezing tissue was performed. The outcome revealed that slow freezing technique caused low tissue survival as well as low follicle counts, probably due to the lyse of the stromal cells and nuclei density between bundles of extracellular fibers. However, no significant differences between fresh and vitrification groups were observed [35]. In Fabbri's study, approximately $30 \%$ of the follicles in the slow freezing group showed signs of degeneration, probably due to osmotic stress [28]. In general, reports have shown that the ratio of healthy follicles and primordial follicle density with the vitrification method is higher than in with slow freezing technique [13]. Due to the high survival and lower level of follicular degeneration [36], vitrification is suggested as the most effective procedure for reserving and freezing ovarian tissue.

\section{Alternatives for ovarian transplantation}

Various fertility preservation options are being offered for patients based on their health conditions. To determine the most appropriate choice, the status of the patient is critically evaluated by the physician [6]. Several options are available for fertility preservation such as egg or embryo cryopreservation, in vitro oocyte/follicle maturation and ovarian transposition or oophoropexy for radiation shielding [6].

Embryo and egg cryopreservation have certain limitations, such as the control of ovarian stimulation and, 
the time required in the ovulation stimulation process when for instance the cancer treatment has to start immediately after diagnosis [8].

In cases of hormone-sensitive malignancies such as several types of breast cancer, ovarian stimulation protocols different from the traditional protocols are required to superovulate and collect the oocytes. However, in young patients before puberty, in which ovarian stimulation protocols are not considered, ovarian tissue preservation is the only possible approach [8].

According to results from various investigations, cryopreservation of ovarian tissue before gonadotoxic treatments for women undergoing chemotherapy or radiotherapy is one of the available approaches to maintain reproductive capacity. This technique is an effective method for reserving and retaining thousands of follicles in the early stages of cancer diagnosis [8]. Preservation of the oocytes, embryos [48] and saving all or some part of the ovaries are steps that have been taken so far [7].

\section{Conclusion}

After getting successful outcomes following ovarian tissue transplantation, researchers have tried to implement new technologies for transplantation surgery, aiming to use the least invasive methods. Hence, using the techniques with the lowest surgical invasion such as robotassisted laparoscopic surgery, present new approaches for ovarian tissue transplantation aiming to reduce probable adverse effects [49]. Considering the results of our investigation, the ovarian tissue cryopreservation and transplantation technique is an applied and developed method for increasing the quality of life for women who are about to lose their fertility, patients diagnosed with premature ovarian failure (POF), and/or women undergoing cancer treatments. According to the results of studies, orthotopic transplantation has been shown to be the most effective method for resuscitation of endocrine function and restoration of fertility.

\section{Abbreviations}

AMH: anti Mullerian hormone; FSH: follicle stimulating hormone; IVF: in-vitro fertilization; LH: luteinizing hormone; PRISMA: Preferred Reporting Items for Systematic Reviews; POF: premature ovarian failure; PCNA: proliferating cell nuclear antigen.

\section{Acknowledgements}

The authors would like to thank the Stem Cell Research Center, Tabriz University of Medical Sciences for supporting this work.

\section{Authors' contributions}

SS, MS, HM, and SA collected data, performed literature review and wrote an initial draft of the manuscript. AMB, ZN, MN, and RR reviewed and revised the initial draft of the manuscript. MM designed and conceptualized the manuscript. All authors read and approved the final manuscript.

\section{Funding}

This manuscript was supported by a grant from Tabriz University of Medical Sciences (Grant No. 59694).

\section{Availability of data and materials}

Not applicable.

Ethics approval and consent to participate

Not applicable.

\section{Consent for publication}

Not applicable.

\section{Competing interests}

The authors declare that they have no competing interests.

\section{Author details}

${ }^{1}$ Department of Midwifery, Faculty of Nursing and Midwifery, Tabriz University of Medical Sciences, Tabriz 5166615739, Iran. ${ }^{2}$ Department of Clinical Sciences, Faculty of Veterinary Medicine, Ferdowsi University of Mashhad, Mashhad 9177948974, Iran. ${ }^{3}$ Department of Biology, Faculty of Science, Azerbaijan Shahid Madani University, Tabriz 537517169, Iran. ${ }^{4}$ Laboratory for Translational Immunology (LTI), Universitair Medisch Centrum Utrecht, (UMCU), Heidelberglaan 100, 3584 CX Utrecht, The Netherlands. ${ }^{5}$ Women's Reproductive Health Research Center, Tabriz University of Medical Sciences, Tabriz 5166615739, Iran. ${ }^{6}$ Department of Applied Cell Sciences, Faculty of Advanced Medical Sciences, Tabriz University of Medical Sciences, Tabriz 5166615739, Iran. ${ }^{7}$ Stem Cell Research Center, Tabriz University of Medical Sciences, Tabriz 5166615739, Iran. ${ }^{8}$ Department of Reproductive Biology, Faculty of Advanced Medical Sciences, Tabriz University of Medical Sciences, Daneshgah St., Tabriz 5166615739, Iran.

Received: 8 August 2019 Accepted: 19 November 2019

Published online: 29 November 2019

\section{References}

1. Anderson RA, Wallace WH, Baird DT. Ovarian cryopreservation for fertility preservation: indications and outcomes. Reproduction. 2008;136:681-9.

2. Howell S, Shalet S. Gonadal damage from chemotherapy and radiotherapy. Endocrinol Metab Clin North Am. 1998;27:927-43.

3. Lambertini M, Del Mastro L, Pescio MC, Andersen CY, Azim HA Jr, Peccatori FA, et al. Cancer and fertility preservation: international recommendations from an expert meeting. BMC Med. 2016;14:1.

4. Shuster LT, Rhodes DJ, Gostout BS, Grossardt BR, Rocca WA. Premature menopause or early menopause: long-term health consequences. Maturitas. 2010;65:161-6.

5. Okeke T, Anyaehie U, Ezenyeaku C. Premature menopause. Ann Med Health Sci Res. 2013;3:90-5.

6. Redig AJ, Brannigan R, Stryker SJ, Woodruff TK, Jeruss JS. Incorporating fertility preservation into the care of young oncology patients. Cancer. 2011;117:4-10.

7. Donnez J, Dolmans MM, Demylle D, Jadoul P, Pirard C, Squifflet J, Martinez-Madrid B, van Langendonckt A. Livebirth after orthotopic transplantation of cryopreserved ovarian tissue. Lancet. 2004;364:1405-10.

8. Kondapalli LA. Ovarian tissue cryopreservation and transplantation, oncofertility medical practice. Berlin: Springer; 2012. p. 63-75.

9. Lee DM, Yeoman RR, Battaglia DE, Stouffer RL, Zelinski-Wooten MB, Fanton JW, Wolf DP. Live birth after ovarian tissue transplant. Nature. 2004;428:137-8.

10. Demeestere I, Simon P, Dedeken L, Moffa F, Tsepelidis S, Brachet C, Delbaere A, Devreker F, Ferster A. Live birth after autograft of ovarian tissue cryopreserved during childhood. Hum Reprod. 2015;30:2107-9.

11. Silber S, Pineda J, Lenahan K, DeRosa M, Melnick J. Fresh and cryopreserved ovary transplantation and resting follicle recruitment. Reprod Biomed Online. 2015;30:643-50.

12. Klocke S, Bundgen N, Koster F, Eichenlaub-Ritter U, Griesinger G. Slowfreezing versus vitrification for human ovarian tissue cryopreservation. Arch Gynecol Obstet. 2015;291:419-26. 
13. Shi Q, Xie Y, Wang Y, Li S. Vitrification versus slow freezing for human ovarian tissue cryopreservation: a systematic review and meta-anlaysis. Sci Rep. 2017;7:8538.

14. Moher D, Liberati A, Tetzlaff J, Altman DG. Preferred reporting items for systematic reviews and meta-analyses: the PRISMA statement. Ann Intern Med. 2009;151:264-9.

15. Dittrich R, Mueller A, Binder H, Oppelt PG, Renner SP, Goecke T, Hoffmann I, Beckmann WM. First retransplantation of cryopreserved ovarian tissue following cancer therapy in Germany. Dtsch Arztebl Int. 2008;105:274-8.

16. Dittrich R, Lotz L, Keck G, Hoffmann I, Mueller A, Beckmann MW, van der Ven $\mathrm{H}$, Montag M. Live birth after ovarian tissue autotransplantation following overnight transportation before cryopreservation. Fertil Steril. 2012;97:387-90

17. Dittrich R, Hackl J, Lotz L, Hoffmann I, Beckmann MW. Pregnancies and live births after 20 transplantations of cryopreserved ovarian tissue in a single center. Fertil Steril. 2015;103:462-8.

18. Müller A, Keller K, Wacker J, Dittrich R, Keck G, Montag M, Van der Ven H, Wachter D, Beckmann MW, Distler W. Retransplantation of cryopreserved ovarian tissue: the first live birth in Germany. Deutsches Arzteblatt international. 2012;109:8-13.

19. Wølner-Hanssen P, Hägglund L, Ploman F, Ramirez A, Manthorpe R, Thuring A. Autotransplantation of cryopreserved ovarian tissue to the right forearm $41 / 2$ years after autologous stem cell transplantation. Acta Obstet Gynecol Scand. 2005;84:695-8.

20. Burmeister $L$, Kovacs GT, Osianlis T. First Australian pregnancy after ovarian tissue cryopreservation and subsequent autotransplantation. Med J Aust. 2013:198:158-9.

21. Revelli A, Marchino G, Dolfin E, Molinari E, Delle Piane L, Salvagno F, Benedetto C. Live birth after orthotopic grafting of autologous cryopreserved ovarian tissue and spontaneous conception in Italy. Fertil Steril. 2013;99:227-30.

22. Kiseleva M, Malinova I, Komarova E, Shvedova T, Chudakov K, Kaprin A. The first Russian case of pregnancy after orthotopic transplantation of vitrified ovarian tissue. Gynecol Endocrinol. 2015;31:91-2.

23. Ernst $E$, Bergholdt $S$, Jørgensen JS, Andersen CY. The first woman to give birth to two children following transplantation of frozen/thawed ovarian tissue. Hum Reprod. 2010;25:1280-1.

24. Oktay K, Türküolu I, Rodriguez-Wallberg KA. Four spontaneous pregnancies and three live births following subcutaneous transplantation of frozen banked ovarian tissue: What is the explanation? Fertil Steril. 2011;95:804.

25. Biasin E, Salvagno F, Berger M, Nesi F, Quarello P, Vassallo E, Evangelista F, Marchino GL, Revelli A, Benedetto C, Fagioli F. Ovarian tissue cryopreservation in girls undergoing haematopoietic stem cell transplant: experience of a single centre. Bone Marrow Transplant. 2015;50:1206-11.

26. Callejo J, Salvador C, Miralles A, Vilaseca S, Lailla JM, Balasch J. Long-term ovarian function evaluation after autografting by implantation with fresh and frozen-thawed human ovarian tissue. J Clin Endocrinol Metab. 2001;86:4489-94

27. Donnez J, Squifflet J, Pirard C, Jadoul P, Dolmans MM. Restoration of ovarian function after allografting of ovarian cortex between genetically non-identical sisters. Hum Reprod. 2010;25:2489-95.

28. Fabbri R, Pasquinelli G, Magnani V, Macciocca M, Vicenti R, Parazza I, Paradisi R, Battaglia C, Rossi S, Venturoli S. Autotransplantation of cryopreserved ovarian tissue in oncological patients: recovery of ovarian function. Future Oncol. 2014;10:549-61.

29. Janse F, Donnez J, Anckaert E, de Jong FH, Fauser BC, Dolmans MM. Limited value of ovarian function markers following orthotopic transplantation of ovarian tissue after gonadotoxic treatment. J Clin Endocrinol Metab. 2011;96:1136-44.

30. Jensen AK, Kristensen SG, MacKlon KT, Jeppesen JV, Fedder J, Ernst E, Andersen CY. Outcomes of transplantations of cryopreserved ovarian tissue to 41 women in Denmark. Hum Reprod. 2015;30:2838-45.

31. Kim SS. Assessment of long term endocrine function after transplantation of frozen-thawed human ovarian tissue to the heterotopic site: 10 year longitudinal follow-up study. J Assist Reprod Genet. 2012;29:489-93.

32. Meirow D, Baum M, Yaron R, Levron J, Hardan I, Schiff E, Nagler A, Yehuda DB, Raanani H, Hourvitz A, Dor J. Ovarian tissue cryopreservation in hematologic malignancy: ten years' experience. Leuk Lymphoma. 2007;48:1569-76
33. Fabbri R, Vicenti R, Paradisi R, Rossi S, De Meis L, Seracchioli R, Macciocca M. Transplantation of cryopreserved ovarian tissue in a patient affected by metastatic struma ovarii and endometriosis. Gynecol Endocrinol. 2018;34:558-62.

34. Meirow D, Ra'anani H, Shapira M, Brenghausen M, Derech Chaim S, AvielRonen S, Amariglio N, Schiff E, Orvieto R, Dor J. Transplantations of frozenthawed ovarian tissue demonstrate high reproductive performance and the need to revise restrictive criteria. Fertil Steril. 2016;106:467-74.

35. Silber S, Kagawa N, Kuwayama M, Gosden R. Duration of fertility after fresh and frozen ovary transplantation. Fertil Steril. 2010;94:2191-6.

36. Suzuki N, Yoshioka N, Takae S, Sugishita Y, Tamura M, Hashimoto S, Morimoto Y, Kawamura K. Successful fertility preservation following ovarian tissue vitrification in patients with primary ovarian insufficiency. Hum Reprod. 2015;30:608-15.

37. Tanbo T, Greggains G, Storeng R, Busund B, Langebrekke A, Fedorcsak P. Autotransplantation of cryopreserved ovarian tissue after treatment for malignant disease - the first Norwegian results. Acta Obstet Gynecol Scand. 2015:94:937-41.

38. Beckmann MW, Dittrich R, Lotz L, Oppelt PG, Findeklee S, Hildebrandt T, Heusinger K, Cupisti S, Muller A. Operative techniques and complications of extraction and transplantation of ovarian tissue: the Erlangen experience. Arch Gynecol Obstet. 2017;295:1033-9.

39. Demeestere I, Simon P, Buxant F, Robin V, Fernandez SA, Centner J, Delbaere A, Englert Y. Ovarian function and spontaneous pregnancy after combined heterotopic and orthotopic cryopreserved ovarian tissue transplantation in a patient previously treated with bone marrow transplantation: case report. Hum Reprod. 2006;21:2010-4.

40. Imbert R, Moffa F, Tsepelidis S, Simon P, Delbaere A, Devreker F, Dechene J, Ferster A, Veys I, Fastrez M, Englert Y, Demeestere I. Safety and usefulness of cryopreservation of ovarian tissue to preserve fertility: a 12-year retrospective analysis. Hum Reprod. 2014;29:1931-40.

41. Povoa A, Xavier P, Calejo L, Soares S, Sousa M, Silva J, Sousa S, Barros A, Beires J. First transplantation of cryopreserved ovarian tissue in Portugal, stored for 10 years: an unexpected indication. Reprod Biomed Online. 2016:32:334-6.

42. Oktay K, Turkcuoglu I, Rodriguez-Wallberg KA. Four spontaneous pregnancies and three live births following subcutaneous transplantation of frozen banked ovarian tissue: what is the explanation? Fertil Steril. 2011;95(804):e807-10.

43. Dittrich R, Mueller A, Maltaris T, Hoffmann I, Magener A, Oppelt PG, Beckmann MW. Hormonal and histologic findings in human cryopreserved ovarian autografts. Fertil Steril. 2009;91:1503-6.

44. Matthews SJ, Picton H, Ernst E, Andersen CY. Successful pregnancy in a woman previously suffering from beta-thalassemia following transplantation of ovarian tissue cryopreserved before puberty. Minerva Ginecol. 2018;70:432-5.

45. Oktay K, Newton H, Gosden RG. Transplantation of cryopreserved human ovarian tissue results in follicle growth initiation in SCID mice. Fertil Steril. 2000;73:599-603.

46. Donnez J, Silber S, Andersen CY, Demeestere I, Piver P, Meirow D, Pellicer A, Dolmans MM. Children born after autotransplantation of cryopreserved ovarian tissue. A review of 13 live births. Ann Med. 2011:43:437-50.

47. Shaw JM, Bowles J, Koopman P, Wood EC, Trounson AO. Fresh and cryopreserved ovarian tissue samples from donors with lymphoma transmit the cancer to graft recipients. Hum Reprod. 1996;11:1668-73.

48. Konc J, Kanyo K, Kriston R, Somoskoi B, Cseh S. Cryopreservation of embryos and oocytes in human assisted reproduction. Biomed Res Int. 2014;2014:307268.

49. Oktay K, Taylan E, Sugishita Y, Goldberg GM. Robot-assisted laparoscopic transplantation of frozen-thawed ovarian tissue. J Minim Invasive Gynecol. 2017;24:897-8.

\section{Publisher's Note}

Springer Nature remains neutral with regard to jurisdictional claims in published maps and institutional affiliations. 